\title{
Electrocrystallization of Copper Powders from Dimethylsulphoxide Aqueous Solutions
}

\author{
AIGUL MAMYRBEKOVA ${ }^{1 *}$, A. MAMITOVA ${ }^{1}$ and AIZHAN MAMYRBEKOVA ${ }^{2}$ \\ ${ }^{1}$ Department of Chemical Engineering and Biotechnology,M. Auezov South Kazakhstan \\ State University, Tauke khan avenue, 5, Shymkent, 160000, Kazakhstan. \\ ${ }^{2}$ Medical Department, A. Yasawi University, B. Sattarkhanov avenue, 29, \\ Turkestan, 161200, Kazakhstan. \\ *Corresponding author E-mail: aigul_akm@mail.ru, aizhan.mamyrbekova@ayu.edu.kz
}

http://dx.doi.org/10.13005/ojc/330411

(Received: June 06, 2017; Accepted: July 05, 2017)

\begin{abstract}
The possibility of the electroprecipitation of copper powder via the cathodic reduction of an electrolyte solution containing copper(II) nitrate trihydrate and dimethylsulfoxide (DMSO) is shown. The effect electrolysis conditions (current density, concentration and temperature of electrolyte) have on the dimensional characteristics of copper powder is studied. The size and shape of the particles of the powders were determined by means of electron microscopy; the qualitative composition of the powders, with thermogravimetric method.
\end{abstract}

Keywords: Dimethylsulfoxide, Copper(II) nitrate trihydrate, Electrolysis, Copper powder, Thermogravimetry

\section{INTRODUCTION}

Among the developing directions of modern researches the particular interest represent finely divided powder. The microstructure of finely divided powder gives them a number of new properties in comparison with usual materials. Recently a great interest represent finely divided powder of copper possessing the specific properties thanks to which their application for creation of new effective materials of different function ${ }^{1}$ is possible. Determination of dependence of structure and properties of produced copper powder from structure of electrolit is actual problems of electrochemistry.

The problem of metal extraction without accompanying (parallel) reaction of hydrogen extraction, characteristic for electrolysis of water solutions, can be solved by using of the solvents possessing higher electrochemical stability, than water. The most suitable in this respect are aprotonic organic solvents which do not contain some mobile hydrogen and are restored at rather high cathodic potentials ${ }^{2-4}$. In this connection, in the given work 
as solvent dimethyl sulfoxide is chosen $\left(\mathrm{CH}_{3}\right)_{2} \mathrm{SO}$, which is cationtropic onnection characterised by high dissolving and ionising ability $(\varepsilon=47)$. It is also known high adsorption activity of solvent on border copper-electrolit 5 .

The review of the literary data has shown that the significant amount of works are devoted to the question of studying of possibility of electrodeposition of copper from non-aqueous mediums ${ }^{6,7}$.

In spite of so extensive list of nonaqueous solvents in which possibility of electrodeposition of copper is proved, the quantity of works on electrodeposition of copper from electrolytes on a basis of dimethylsulphoxide or mixtures of DMSO with other compounds are small. Great attention of researchers has aprotonic solvents, in particular dimethylsulphoxide ${ }^{8-10}$. Organic dipolar solvents possess the ability to form the complexes with some ds-metals and high adsorb ability on metals. Molecules of $\left(\mathrm{CH}_{3}\right)_{2} \mathrm{SO}$, being cation tropic, form strong enough complexes with copper ions (II). The analysis of electronic structure of molecules of $\left(\mathrm{CH}_{3}\right)_{2} \mathrm{SO}$ and features of a metal lattice of copper allow to make the conclusion about the most probable orientation of adsorbed molecules of DMSO by atom of oxygen to metal. The electrolyte offered in the given work received by dissolution of copper(II) nitrate trihydrate $\mathrm{Cu}\left(\mathrm{NO}_{3}\right)_{2} \cdot 3 \mathrm{H}_{2} \mathrm{O}$ in DMSO, differs by simplicity of structure and thanks to presence of surface-active and complexing properties of ions $\mathrm{Cu}^{2}+$ and $\mathrm{NO}_{3}^{-}$with solvent, does not require introduction of other additives influencing on kinetics of reduction of copper.

The aim of this work was to obtain fine powders of copper from dimethylsulfoxide aqueous solutions with particle sizes of up to $50 \mathrm{im}$, and to study their physicochemical properties.

\section{MATERIALS AND METHODS}

Electrocrystallization of copper powder were spent in solutions of copper(II) nitrate trihydrate in DMSO. Used in work trihydrate was synthesized by a technique ${ }^{11}$ and was purified by recrystallization from a water solution. Chemical pure DMSO was exposed to vacuum distillation $\left(n_{D}{ }^{25}=1.4816\right)$. The prepared solutions of electrolytes before electrolysis were held not less than a day for achievement in system of ionic balance.

Electrodeposition of copper powder was spent in galvanostatic regime in temperaturecontrolled glass box equipped by viniplast cover with parallel fixed anodes, without forced mixing. A steel cylindrical core, placed in the cover centre, was used as the cathode. The plates made from electrical pure copper were used as the soluble anodes. The advantage of application of soluble anodes is the possibility of electrolysis carrying out for enough a long time.

After the termination of electrolysis the received precipitate was repeatedly washed out by bidistilled water till constant value of conductivity of washing water and dried up till powder with constant weight.

The size and the form of particles of the received powder were determined by electronic microscopy. In work raster electronic microscope JSM 6490 LA was used that increases in 2000 and 5000 times.

For studying of the distribution by the sizes of copper powder particles the laser analyzer of mark LS 13320 with the water module was used. The range of measurement of the size of particles fluctuates from 0.020 microns to 200 microns. For measuring of particles by diffraction method the laser light with the length of a wave of 750 nanometers, generated in the ultrasonic radiator of the device LS 13 320, was used.

X-ray structural analysis of electrolytic powder copper is executed on diffractometer DRON-2.0 (monochromatic $\mathrm{Cu \kappa}_{\alpha}$ - emission). Speed of rotation of the counter is $2 \mathrm{deg} / \mathrm{min}$.

Polarization measurements were spent in potentiodynamic regime with use of potentiostat PI-50-1. Speed of development of potential is $5 \mathrm{mV} / \mathrm{second}$. The platinum wire was used as working electrode on which in standard conditions by electrolytic way a layer of copper with the thickness of 18-20 microns was electroplated ${ }^{12}$. As a comparison electrode the silver electrode $\mathrm{Ag} / 0.01 \mathrm{M} \mathrm{AgNO}_{3}$ in DMSO was used which potential is measured in 
relation to saturated mercurial sulphatic electrode $\mathrm{Hg} / \mathrm{Hg}_{2} \mathrm{SO}_{4}, 1 \mathrm{n} \mathrm{H}_{2} \mathrm{SO}_{4}$ and in recalculation on a hydrogen scale it was $+0.3 \mathrm{~V}$.

Thermogravimetric researches of cupriferous powders were conducted on «Microthermoweights TG $209 \mathrm{~F} 1$ » in the temperature range from 20 to $960{ }^{\circ} \mathrm{C}$. Heat rate of an exemplar made $10 \mathrm{~K} / \mathrm{min}$. Heating of powders was made in the atmosphere of air and the atmosphere of argon. Under the chosen experimental conditions the error made: at change of temperature of an exemplar $\pm 0.1 \mathrm{~K}$; at change of mass of an exemplar $\pm 5 \AA .10^{-3} \mathrm{mg}$. Calorimetric measurements were taken on the differential scanning calorimeter (DSC) of the DSC 204 F1 brand of $\mathrm{NETZSCH}$ in the range of temperatures from 20 to $600^{\circ} \mathrm{C}$ in the atmosphere of air and argon. The definition error $\Delta \mathrm{H}$ process made \pm 0.1 $\mathrm{J} / \mathrm{g}$. Powder with the greatest number of particles less than 100 nanometers in size was investigated by methods of an electron diffraction investigation, roentgenography and thermogravimetric.

\section{RESULTS AND DISCUSSIONS}

The researches of volume and transport properties of solutions of copper(II) nitrate trihydrate in DMSO have shown that the maximum of conductivity is observed in $0.4 \mathrm{M}$ solution of copper(II) nitrate in DMSO at $15^{\circ} \mathrm{C}$ that is changed till $0.6 \mathrm{M}$ at higher temperature ${ }^{13}$. In this connection, for studying of possibility of electrodeposition of copper powder from dimethylsulphoxide the interval of concentration of copper salt was chosen
0.1-0.6 M. In solutions with concentration of $0.5 \mathrm{M}$ of copper salt in DMSO and higher the viscosity is considerably raised that reduces the mobility of ions of metal.

In electrolyte for producing of copper powder, as a result of interaction of components the ions of copper(II), nitrates-ions, and also solvated complexes $\left[\mathrm{Cu}(\mathrm{DMSO})_{4}\left(\mathrm{H}_{2} \mathrm{O}\right)_{2}\right]^{2+}$ and ion-adducts $\left[\left(\mathrm{CH}_{3}\right)_{2} \mathrm{SONO}_{3}\right]^{-}$are possibly formed ${ }^{14}$, causing electroconductivity of solution. Influence of dimethylsulphoxide on electrocrystallization of copper powder is connected, obviously, with its surface-active and chelating properties.

Laws of kinetics of cathodic processes of electrochemical deposition of copper from dimethylsulphoxide solutions of copper nitrate trihydrate was studied in potentiodynamic regime in $0.4 \mathrm{M}$ solution of $\mathrm{Cu}\left(\mathrm{NO}_{3}\right)_{2} \cdot 3 \mathrm{H}_{2} \mathrm{O}$ in DMSO at temperatures $25-55^{\circ} \mathrm{C}$.

At temperature of $25{ }^{\circ} \mathrm{C}$ the cathodic voltage-ampere curves are the curves with two accurately expressed maximums of currents that proves the two-step discharge of solvated complexes of copper(II) $\left[\mathrm{Cu}(\mathrm{DMSO})_{4}\left(\mathrm{H}_{2} \mathrm{O}\right)_{2}\right]^{2+}$ on electrode adsorbed by molecules of dimethylsulphoxide that schematically can be presented as:

$$
\begin{array}{ll}
\mathrm{Cu}^{2+}+\mathrm{e}^{-}=\mathrm{Cu}^{+} & E=-0.1 \div-0.2 \mathrm{~B} \\
\mathrm{Cu}^{2+}+\mathrm{e}^{-}=\mathrm{Cu}^{0} & E=-0.3 \div-0.5 \mathrm{~B}
\end{array}
$$

Table 1: Electrolytes compound and condition of electrolysis of precipitation of copper powder

\begin{tabular}{lllllll}
\hline $\begin{array}{l}\mathbf{N}^{0} \text { of expe. } \\
\text { riment }\end{array}$ & $\begin{array}{l}\text { Concentrationof } \\
\text { copper nitrate (II) } \\
\text { trihydrate mol/I }\end{array}$ & DMSO & $\begin{array}{l}\text { Cathodic } \\
\text { current } \\
\text { density, } \\
\mathbf{A} / \mathbf{m}^{2}\end{array}$ & $\begin{array}{l}\text { Temperature, } \\
{ }^{\circ} \mathbf{C}\end{array}$ & $\begin{array}{l}\text { Sizes of } \\
\text { powder, } \\
\text { particles } \\
\text { microns }\end{array}$ & $\begin{array}{l}\text { Current } \\
\text { yield, \% }\end{array}$ \\
\hline & & & & & & \\
1. & 0.1 & till 1 I & 400 & 25 & 30 & 96.8 \\
2. & 0.15 & till 1 I & 500 & 30 & 30 & 95.7 \\
3. & 0.2 & till 1 I & 600 & 35 & 40 & 94.5 \\
4. & 0.25 & till 1 I & 700 & 40 & 40 & 93.6 \\
5. & 0.3 & till 1 I & 800 & 25 & 40 & 96.6 \\
6. & 0.35 & till 1 I & 900 & 30 & 30 & 96.2 \\
7. & 0.4 & till 1 I & 1000 & 25 & 30 & 98.7 \\
8. & 0.45 & till 1 I & 1100 & 25 & 30 & 98.7 \\
\hline
\end{tabular}


Formation of dimethylsulphoxide complexes of copper(II) and formation of enough dense adsorbed layer on the cathode, consisting of molecules of organic solvent lead to certain braking and shift of potential of restoration of copper(II) ions in more electronegative area $(E=-0.5 \mathrm{~B})$ and promotes formation of finely divided copper powder.

At temperatures $35-55{ }^{\circ} \mathrm{C}$ the third wave which lies in deeper area of electronegative potentials is observed on polarising curves. Probably this maximum corresponds to restoration of nitratesions:

$\mathrm{NO}_{3}^{-}+\mathrm{H}_{2} \mathrm{O}+2 \mathrm{e}^{-}=\mathrm{NO}_{2}^{-}+2 \mathrm{OH}^{-} \quad \mathrm{E}=-1.2 \div-1.3$

Rise of temperature till $35^{\uparrow} \mathrm{C}$ and higher, obviously, promotes partial desorption of solvent, hydrogen bond opening between molecules of $\mathrm{H}_{2} \mathrm{O}$ and $\left(\mathrm{H}_{3} \mathrm{C}\right)_{2} \mathrm{SO}$, causing destruction of heteronuclear complexes, also the fluctuations of structure connected with disintegration of nitrate complexes strengthen. Hence, these processes promote to acceleration of process of nitrates-ions restoration, less solvated by molecules of organic solvent, that causes their great reactivity with temperature growth.

With increase of concentration of copper(II) salt in organic solvent the offset of cathodic potential to more electronegative meanings is observed that leads to decrease of maximums and sizes of cathodic currents. The given phenomenon is possible to explain by increase of viscosity of solution, decrease of dissociation degree of copper(II) nitrate trihydrate in DMSO, and also reduction of copper ions diffusion coefficient. $(>0.6 \mathrm{M})$ the ionic association is strengthened that cause the viscosity increase, reduction of dielectric permeability and decrease of electroconductivity, established earlier ${ }^{15}$.

For deposition of disperse copper the electrolytes, which structures and conditions of electrolysis are resulted in Table 1 were used.
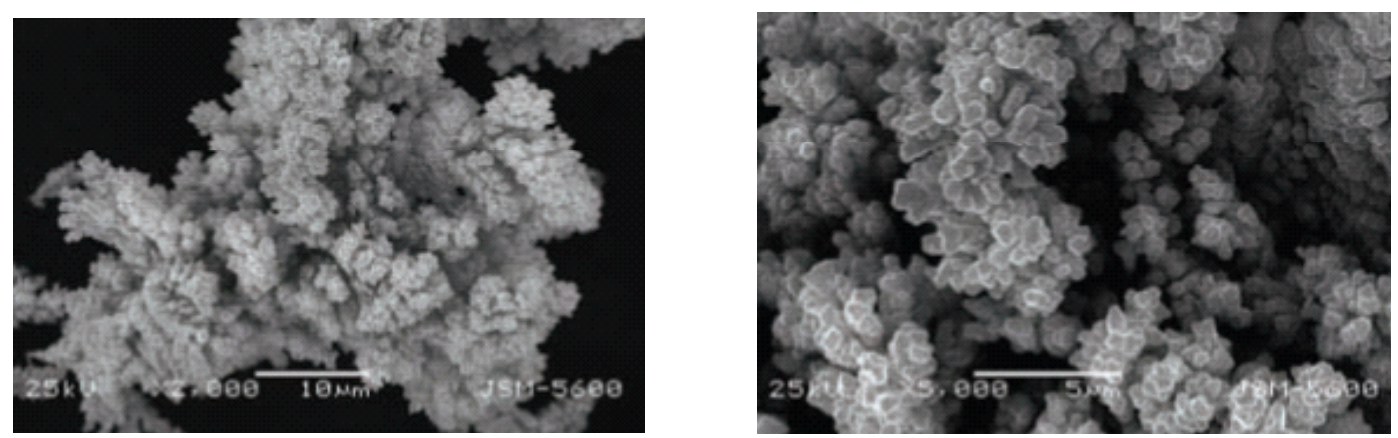

Fig. 1: Morphology of copper powder produced from $0.4 \mathrm{M}$ solution of copper(II) nitrate trihydrate in DMSO and current density $i_{k}=900 \mathrm{~A} / \mathrm{m}^{2}(a-x 2000, b-x 5000)$
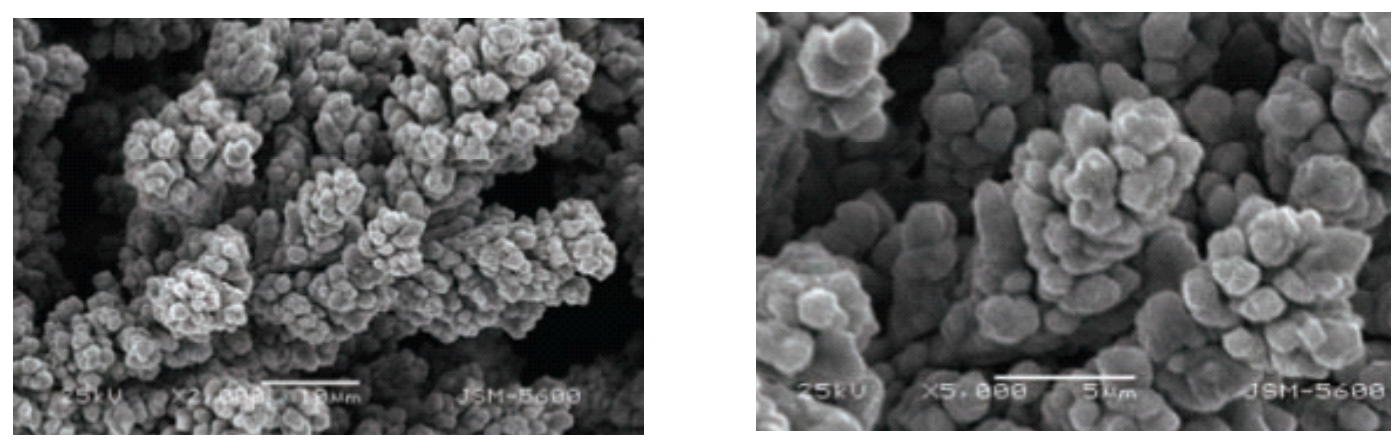

Fig. 2: Morphology of copper powder produced from $0.4 \mathrm{M}$ solution of copper(II) nitrate trihydrate in DMSO and current density $i_{k}=1000 \mathrm{~A} / \mathrm{m}^{2}(a-x 2000, b-x 5000)$ 
The size and the form of particles of the received powder were determined by the microphotos, received by raster electronic microscope JSM 6490 LA. For each preparation of copper powder, received after electrolysis, some microphotos were made that provided possibility of determination of disperse structure of powder (Fig. 1-3).

By results of a big series of experiments built histograms of particle size distribution (Fig. 4,5). $85-90 \%$ of particles measure $20-100 \mathrm{~nm}$, the quantity of larger particles makes 10-15\% of total amount. By results of the analysis of distribution of sizes of cupriferous powders it is possible to make the conclusion that the quantity of particles with sizes from 20 to $500 \mathrm{~nm}$ practically does not depend on material of anodes. It is apparent that the crucial role in formation of ultradispersible particles is played by concentration of electrolyte. In the technological plan and perspective carrying out an electrolysis with soluble (copper) anodes is more economic. Optimum concentration of electrolyte for electrochemical synthesis of ultradispersible powders makes $0,4 \mathrm{M}$.

As appears from the data of thermogravimetric analysis on curve of change of mass of an exemplar in the atmosphere of air it is possible to allocate two sites for the powder received with use of both soluble, and insoluble anodes. The first site is in an interval of temperatures to $200^{\circ} \mathrm{C}$ which shows slight decrease of mass of an exemplar, the bound to solvent evaporation. The second site at temperatures above $200^{\circ} \mathrm{C}$ corresponds to increase in mass of an exemplar owing to oxidation of
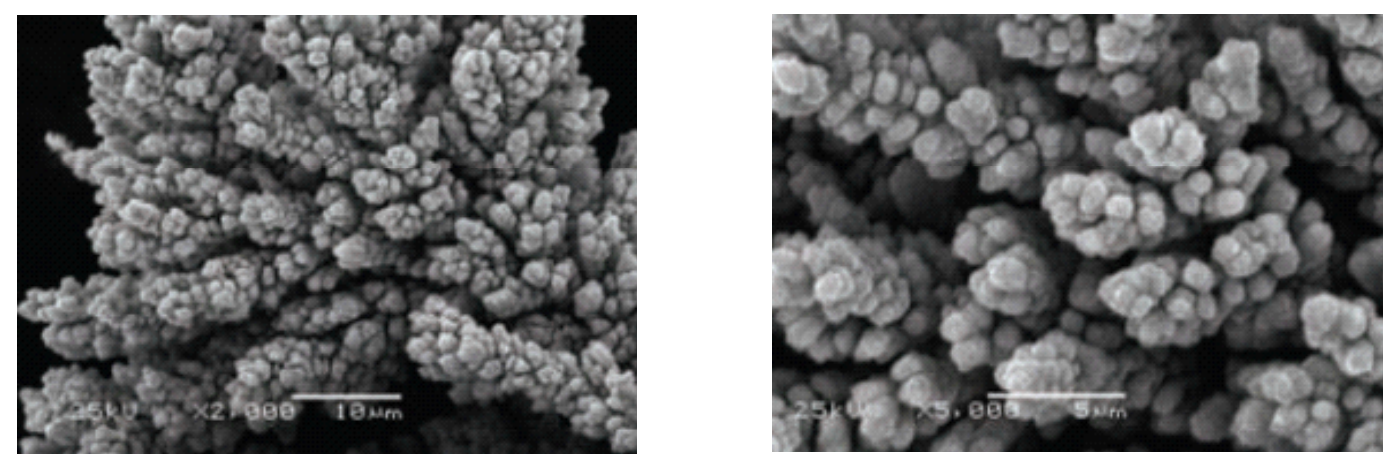

Fig. 3: Morphology of copper powder produced from $0.4 \mathrm{M}$ solution of copper(II) nitrate trihydrate in DMSO and current density $i_{k}=1100 \mathrm{~A} / \mathrm{m}^{2}(a-x 2000, b-x 5000)$

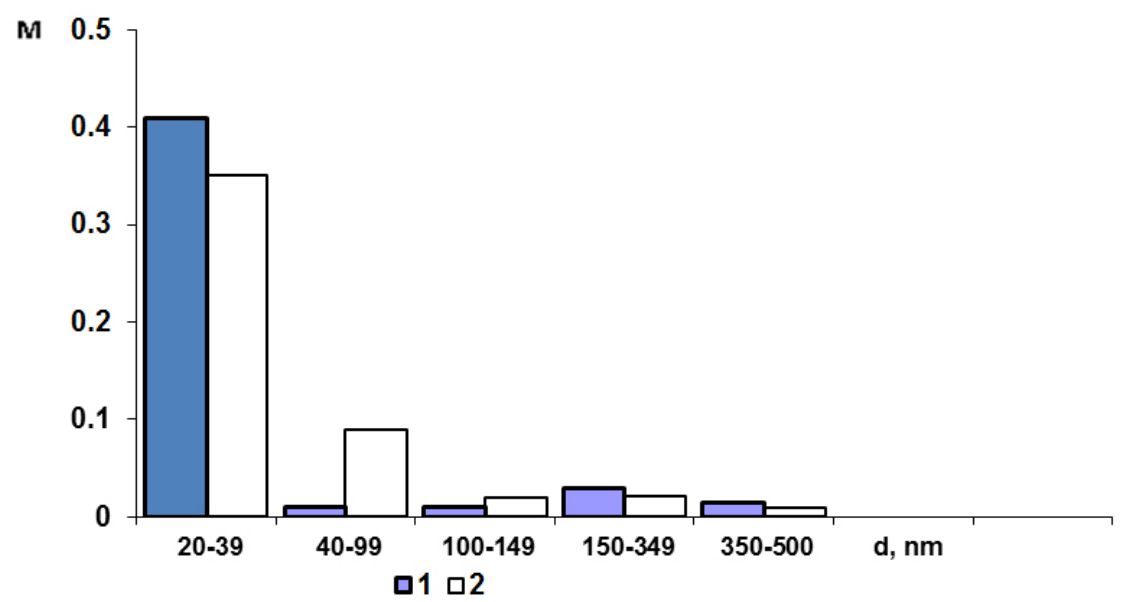

Fig. 4: Histograms of particle size distribution for the powders produced at $25^{\circ} \mathrm{C}$ : 1 - the powder received with use of insoluble anodes; 2 - the powder received with use of soluble anodes 


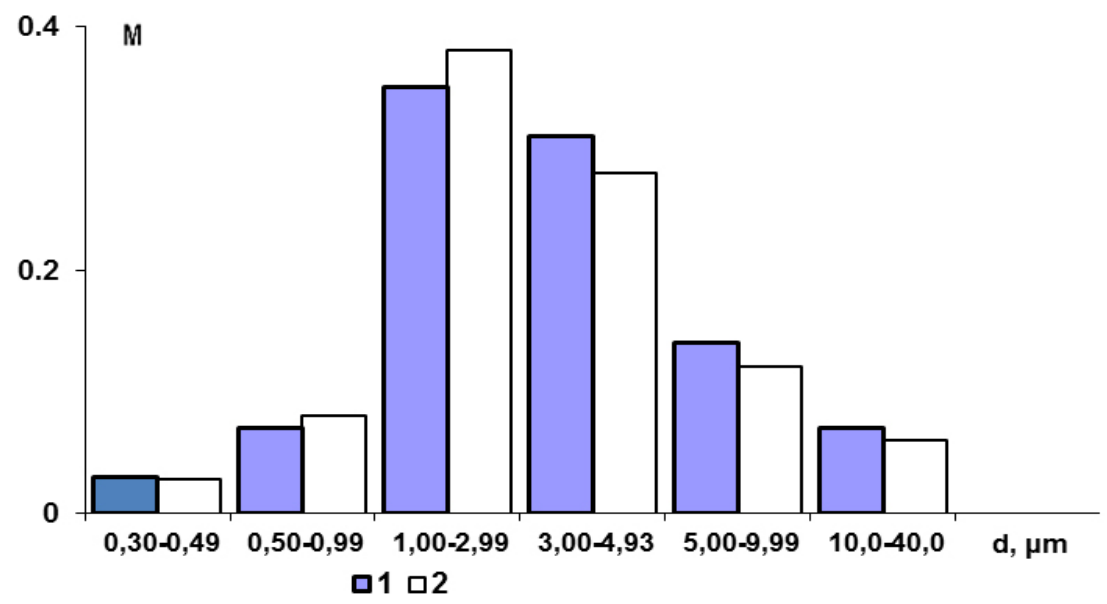

Fig. 5: Histograms of particle size distribution for the powders produced at $35^{\circ} \mathrm{C}$ : 1 - the powder received with use of insoluble anodes; 2 - the powder received with use of soluble anodes

components of powder. On curve of change of mass of an exemplar when heating in the atmosphere of argon for the powder received with use of a soluble anode in all temperature range (from 20 to $940^{\circ} \mathrm{C}$ ) decrease of mass of an exemplar, the bound to gradual evaporation of solvent is observed.

Results of research by the DSK method of the powder received with use of soluble anode showed that it is also possible to allocate two intervals for curve DSK. In temperature range from 20 to $220^{\circ} \mathrm{C}$, on curve the minimum corresponding to thermonegative process (solvent evaporation) is noted. At further increase in temperature up to $600{ }^{\circ} \mathrm{C}$ the excess and a maximum corresponding to intensive exothermic processes, the bound to oxidation of components of powder are observed. At a temperature $\sim 400{ }^{\circ} \mathrm{C}$ there is an oxidation of copper to $\mathrm{CuO}$ on the following equation of reaction:

$2 \mathrm{Cu}+\mathrm{O}_{2}=2 \mathrm{CuO}$

At further heating are observed to oxidation of $\mathrm{Cu}_{2} \mathrm{O}$ to $\mathrm{CuO}$ and oxidation of copper to $\mathrm{Cu}_{2} \mathrm{O}$ on the following equation of reaction:
$2 \mathrm{Cu}_{2} \mathrm{O}+\mathrm{O}_{2}=4 \mathrm{CuO}$

$4 \mathrm{Cu}+\mathrm{O}_{2}=2 \mathrm{Cu}_{2} \mathrm{O}$

Upon termination of thermogravimetric experiments in a crucible there is a powder of black color which corresponds to $\mathrm{CuO}$. By results of the conducted researches of physical and chemical properties of the ultradispersible cupriferous powders received by an electrochemical cathodic deposition it is established that anode material practically does not influence their chemical composition and dimensional characteristics.

\section{CONCLUSION}

Fine copper powders with particle sizes of $50 \mu \mathrm{m}$ were obtained from dimethylsulfoxide aqueous solutions via electrochemical synthesis, and their physicochemical properties were studied. It was found that the powders obtained from 0.1-0.4 M solutions of $\mathrm{Cu}\left(\mathrm{NO}_{3}\right)_{2} \cdot 3 \mathrm{H}_{2} \mathrm{O}$ in DMSO contained the maximum amount of particles with sizes of $30-40 \mu \mathrm{m}$. According to thermogravimetric measurements, the resulting powders contain $\mathrm{Cu}$, $\mathrm{CuO}$ and $\mathrm{Cu}_{2} \mathrm{O}$. 


\section{REFERENCES}

1. Sosnovsky, G.N.; Sosnovsky, N.G. Electrolytic production of metal powder and electrolysis of the melted mediums. Angarsk, Academic Publishers, 2006, 245.

2. Tesakova, M.V.; Parfenjuk, V.I. News of High schools, Chemistry and chemical technology 2010, 53, 106.

3. Nomberg, M.I. Production of a copper powder by electrolytic way. Moscow, Metallurgy, 1971, 280.

4. Demeyev, B.B.; Nurmanova, R.A.; Kaltaev, N.A. Bulletin of KazNU, chemical series 2012, 365.

5. Vahidov, R.S. Electrochem. 1994, 30, 1165.

6. Akpanbayev, R.S.; Brajendra Mishra; Baikonurova, A.O. Int. J. Electrochem. Sci. 2013, 8, 3150.

7. Vnukov, A.A.; Demchenko, E.I. Bull. of Kharkiv national automobile and road university 2010, 51, 147.
8. Karapetjan, U.A.; Ejchis, V.N. Physical and chemical properties of electrolytic nonaqueous solutions. Moscow, Chemistry, 1989. 450.

9. Schlafer, H.L.; Schaffernicht, W. Angew. Chem. 1990, 72, 618.

10. Kinsinger, J.B.; Tannahill, M.M.; Greenberg, M.S. J. Phys. Chem. 1973, 77, 2444.

11. Karyakin, U.V.; Angelov, I.I. Pure chemical substances. Moscow, Chemistry, 1974, 245.

12. Kudryavtseva, V. N.; Varypaev, V. N. Practical work on applied electrochemistry. Moscow, Chemistry, 1990, 340.

13. Mamyrbekova, A.K. Russ. J. Phys. Chem. 2013, 87, 414.

14. Martin, D.; Haupthal, H. Dimethylsulfoxid. Berlin, Academie - Verlag, 1981, 345.

15. Mamyrbekova, A.K. Russ. J. Gen. Chem. 2013, 83, 1799. 